\title{
A Theoretical Concept of Compositional Nutrient Diagnosis
}

\author{
L.E. Parent ${ }^{1}$ and M. Dafir ${ }^{2}$ \\ Department des Sols, Paul-Comtois Building; Universite' Laval, Sainte-Foy (Que'. ) GIK 7P4 \\ Canada \\ Additional index words. DRIS, critical value approach, compositional data sets
}

\begin{abstract}
The premises underlying univariate $(\mathrm{CVA}=$ critical value approach) and bivariate (DRIS $=$ diagnosis and recommendation integrated system) diagnostic systems were reexamined with regard to compositional data analysis (CDA). CDA recognizes a structure of dependence among plant nutrients, the bounded sum constraint to one (the whole composition equals $100 \%$ or 1 ), and removes the curvature problem carried by crude components and by dual ratios or logratios when treated in isolation. Linearization by "rowcentered logrationing" of nutrient fractions shows great potential for carrying multivariate diagnosis and principal component analysis on nutrient data. Compositional nutrient diagnosis (CND) is supported by the theory of CDA. CND is the multivariate expansion of CVA and DRIS and is fully compatible with PCA. CND takes all possible nutrient interactions into account. CND nutrient indices are composed of two separate functions, one considering differences between nutrient levels, another examining differences between nutrient balances (as defined by nutrient geometric means), of individual and target specimens. These functions indicate that nutrient insufficiency can be corrected by either adding a single nutrient or taking advantage of multiple nutrient interactions to improve nutrient balance as a whole. A theoretical interpretative table is presented for CND.
\end{abstract}

Mineral composition of plant tissues, expressed as concentrations or relative (ratio) values, forms the basic numerical information for diagnosing nutrient status in plants. Bates (1971) reported that the CVA to the interpretation of nutrient deficiency, sufficiency, or excess was affected to a large extent by nutrient interactions and plant age. DRIS was found to improve diagnosis as compared with CVA by taking into account dual interactions expressed as nutrient ratios (Walworth and Sumner, 1987). Inconsistency between CVA and DRIS has been reported (Alkoshab et al., 1988; Beverly, 1987a), but DRIS generally shows greater diagnostic efficiency (Walworth and Sumner, 1989).

Beverly (1987a, 1987b) used the logarithmic transformation to improve data distribution of nutrient ratios from population data to generate DRIS norms. When dry matter values (DM) are identical over all nutrients components, i.e., in individual plant tissues, dual logratioing can provide a single correction factor for a nutrient $\mathrm{x}_{\mathrm{i}}$ given another nutrient $\mathrm{x}_{\mathrm{k}}$ in conformity with the DRIS approach:

$$
\log \left(\mathrm{x}_{\mathrm{i}} / \mathrm{x}_{\mathrm{k}}\right)=\log \left(\mathrm{x}_{\mathrm{i}}\right)-\log \left(\mathrm{x}_{\mathrm{k}}\right)
$$

Holland (1966) observed that as the number of nutrients to be examined simultaneously increases, the consistency of diagnosis increases until the method of interpretation involves all nutrients. "He concluded that a reasoned application of principal component analysis, possibly after logarithmic transformation to linearize functions of original variates, could improve the understanding of leaf composition as compared with any examination of nutrients by univariate (CVA), bivariate (dual ratios or logratios as of DRIS), or trivariate (ternary diagrams) diagnostic tools. Indeed, the constancy of forms of nutrient expression has still not been adequately researched, and the premises underlying interpretation of foliar analysis as practiced today should be reexamined (Walworth and Sumner, 1989).

\footnotetext{
Received for publication 12 July 1991. Accepted for publication 12 Nov. 1991. The research was supported by the Natural Sciences and Engineering Research Council of Canada. The cost of publishing this paper was defrayed in part by the payment of page charges. Under postal regulations, this paper therefore must be hereby marked advertisement solely to indicate this fact.

'Professor.

${ }^{2}$ Graduate student.
}

Aitchison (1986) showed that the study of geological data must be concerned with relative values of rock components summing up to one. A structure of dependence forms among compositional data, since any variation in any one part of a whole must affect the relative values of other parts of the whole. This closure problem, which is referred to as the "bounded sum constraint," causes curvature in linear models. Recognizing that tissue composition is a compositional data set that forms a structure of dependence and frequently displays marked curvature, linear techniques for handling such compositional data are likely to be inadequate (Aitchison, 1983) and might lead to doubtful or distorted inferences (Aitchison, 1986). The notion of nutrient interaction described mathematically by Eq. [1] can be expanded to all components of a compositional data set by correcting any nutrient $\mathrm{x}_{\mathrm{i}}$ for the geometric mean $\mathrm{g}(\mathrm{x})$ of all $\mathrm{D}$ nutrients of a compositional array, a procedure called row-centered logratioing, to generate a new variable, $\mathrm{Z}_{\mathrm{i}}$ :

$$
\mathrm{g}(\mathrm{x})=\left(\mathrm{x}_{1}^{*} \ldots * \mathrm{x}_{\mathrm{D}}\right)^{(\mathrm{I} / \mathrm{D})}
$$

and

$$
\mathrm{Z}_{\mathrm{i}}{ }{ } \log \left[\mathrm{X}_{\mathrm{i}} / \mathrm{g}(\mathrm{X})\right]
$$

The $Z_{\mathrm{i}}$ values can be used either to compute nutrient norms (mean and SD of $\mathrm{z}_{\mathrm{i}}$ values characterizing a performing plant population) or in conjunction with principal component analysis to reduce dimensionality of the compositional array.

The concept of CND differs from the DRIS concept. CND provides a correction factor $\mathrm{g}(\mathrm{x})$ for any nutrient, given all the nutrients under analysis (multinutrient ratio), while DRIS provides a single correction factor for any nutrient given information about another nutrient (dual ratio). In addition, CND generates new variables, the $\mathrm{Z}_{\mathrm{i}}$ values, amenable to multivariate analysis of tissue compositional data.

This paper presents CND and its potential for improving tissue diagnosis as compared with univariate (CVA) or bivariate (DRIS) approaches.

\footnotetext{
Abbreviations: CDA, compositional data analysis; CND, compositional nutrient diagnosis; CVA, critical value approach; DRIS, diagnosis and recommendation integrated system.
} 
Compositional data analysis. Aitchison (1989, 1990) stated three axioms of compositional data analysis: 1) a composition contains information only about the relative, not absolute, magnitudes of components that, as expressed as fractions of a whole, are constrained to a unit-sum; 2) any discussion of the variability of a compositional array can be expressed in terms of ratios of components that should not be considered in isolation; and 3) no information about a composition is lost if logarithms of ratios are studied instead of the ratios themselves.

Axioms 1 and 2 concern the study of composition in terms of ratios of components rather than in terms of crude components to free the variates from the unit-sum or closure (curvature) problem (Aitchison, 1989). Axion 3 simplifies the statistical description of compositional data sets, since the variance of any $\mathrm{x}_{\mathrm{i}} / \mathrm{x}_{\mathrm{k}}$ logratio is made independently of the way the ratio is expressed, i.e., $\operatorname{var}\left[\log \left(\mathrm{x}_{\mathrm{i}} / \mathrm{x}_{\mathrm{k}}\right)\right]=\operatorname{var}\left[\log \left(\mathrm{x}_{\mathrm{k}} / \mathrm{x}_{\mathrm{i}}\right)\right]$ (Aitchison, 1990).

Given D components of an individual specimen, a full composition vector $\mathrm{x}^{(\mathrm{D})}$ can be represented by the $\mathrm{D}$-dimensional simplex SD (Aitchison, 1986):

$$
\begin{gathered}
S^{D}=\left[\left(x_{1}, \ldots, x_{D}\right): x_{1}>0, \ldots, x_{D}>0 ;\right. \\
\left.x_{1}+\ldots+x_{D}=1\right]
\end{gathered}
$$

where $x_{D}$ is the "filling-up value." Since $x_{D}$ is computed by difference between 1 and known fractions of the parts, a D-part composition is a $d=(D-1)$ dimensional vector completely specified by components of the d-part diminished vector $\mathrm{x}^{(\mathrm{d})}$. Any subvector $\mathrm{x}^{(\mathrm{c})}$ with its elements resealed so that their sum is constrained to one is a subcomposition (Aitchison, 1984).

For a plant tissue, the simplex of parts and corresponding fractions may be defined in a number of ways:

$$
\begin{gathered}
S^{\text {D }}=\left[\left(\mathrm{N}, \mathrm{P}, \mathrm{K}, \ldots \mathrm{H}_{2} 0, \mathrm{C}\right): \mathrm{N}>0, \mathrm{P}>0, \mathrm{~K}>0, \ldots \mathrm{H}_{2} 0>0,\right. \\
\left.\mathrm{C}>0 ; \mathrm{N}+\mathrm{P}+\mathrm{K}+\ldots+\mathrm{H}_{2} \mathrm{O}+\mathrm{C}=1\right]
\end{gathered}
$$

is the simplex for fresh tissues. For dry tissues, the component $\mathrm{H}_{2} \mathrm{O}$ is removed from the simplex. If only nutrients are retained, the simplex describes a subcomposition:

$$
\mathrm{S}^{\mathrm{D}}=[(\mathrm{N}, \mathrm{P}, \mathrm{K}, \ldots): \mathrm{N}>0, \ldots ; \mathrm{N}+\mathrm{P}+\mathrm{K}+\ldots<1] .
$$

The sum of nutrient fractions can be resealed so that their sum is constrained to one.

A way to obtain a symmetric treatment of all D-parts is to use the geometric mean $\mathrm{g}(\mathrm{x})$ as the single component divisor (Aitchison, 1986).

$$
\mathrm{g}(\mathrm{x})=\left[\mathrm{x}_{1}^{*} \ldots * \mathrm{x}_{\mathrm{D}}\right]^{(\mathrm{IID})}
$$

Asymmetric vector of row-centered logratios consists of a transformation of any $x_{i}$ into $Z_{i}$, a unitless variate:

$$
\mathrm{Zi}{ } \log \left[\mathrm{X}_{\mathrm{i}} / \mathrm{g}(\mathrm{X})\right]
$$

where $\mathrm{i}$ varies from 1 to $\mathrm{D}$, and

$$
\sum_{i=1}^{D} z_{i}=0
$$

which confirms symmetry.

According to Aitchison (1986), the difficulty of the unit-sum constraint is effectively removed at the step of transforming $\mathrm{Xi}$ into row-centered logratios $Z_{\mathrm{i}}$ using Eq. [2]. Because the rowcentered logratio transformation removes the effect of the constraint on the interpretation of covariance, it is possible to define distances between observations in a way that is not possible with crude components (Jolliffe, 1986).
A tissue subcomposition array of diagnostic significance should attempt to retain as much as possible of the variability of the complete compositional data set related to plant performance. Subcompositional analysis can allow the generation of descriptive statistics (means and SD) about subcomposition of selected tissue specimens. Also, a space of reduced dimensions of rowcentered logratio data can be built in principal component coordinates and mapped to localize areas of high crop performance. Compositional data analysis using principal component analysis could thus be a starting point for CND, since only compositional data sets situated outside the area of high crop performance should be diagnosed.

Relationship between CND and CVA. Crude components are expressed as percentages relative to dry matter (DM). The logarithmic transformation often improves distribution patterns of nutrient concentrations and ratios (Beverly, 1987b). As mentioned earlier, dual logratioing can provide a single correction factor for a nutrient xi given another nutrient $\mathrm{x}_{\mathrm{k}}$ due to a straightforward DM elimination:

$$
\log \left(\mathrm{x}_{\mathrm{i}} / \mathrm{DM}\right)=\log \left(\mathrm{xi}_{\mathrm{i}}\right)-\log (\mathrm{DM})
$$

and

$$
\log \left(\mathrm{X}_{\mathrm{i}} / \mathrm{X}_{\mathrm{k}}\right)=\log \left(\mathrm{X}_{\mathrm{i}}\right)-\log \left(\mathrm{X}_{\mathrm{k}}\right) .
$$

Equation [4] is an expansion of Eq. [3] to include two D elements from a subcompositional nutrient data set. Equation [4] can be further expanded to create a new variable $\mathrm{v}_{\mathrm{i}}$ by including all possible nutrient ratios from the $\mathrm{D}$ nutrients that compose a data set:

$$
\mathrm{Vi}=\left[\mathrm{D} * \log \left(\mathrm{x}_{\mathrm{i}}\right)\right]-\left[\log \left(\mathrm{x}_{\mathrm{l}}\right)+\ldots+\log \left(\mathrm{x}_{\mathrm{D}}\right)\right]
$$

Dividing $\mathrm{v}_{\mathrm{i}}$ by $\mathrm{D}$, we obtain $\mathrm{Z}_{\mathrm{i}}$ as in Eq. [2]. Thus, CND provides a multivariate correction procedure for the univariate CVA approach.

Indeed, Eqs. [3] and [4] fail to recognize: 1) features of variability connected with higher-dimensional space (i.e., mutual effects of changes in relative fraction values of components within a holistic structure); 2) higher-order interactions; 3) graphical distortion or curvature related to the unit-sum constraint; 4) spurious correlations between variates having the same denominators as in Eq. [3]; and 5) the negative bias among covariances and correlations.

Equation [2] overcomes these five difficulties (Aitchison, 1986). Therefore, CND should represent considerable progress over CVA. By taking into account all possible nutrient interactions and canceling out the dry matter component, CND alleviates two major concerns about the critical value approach: nutrient interactions and dilution effects on nutrient levels of diagnosed tissues (Walworth and Sumner, 1987).

Relationship between $C N D$ and DRIS. DRIS is a bivariate method defining norms as the mean and $\mathrm{CV}$ of dual nutrient ratios of crude components characterizing diagnostic tissues of top-yielding crops (Walworth and Sumner, 1987). DRIS proceeds by calculating successively DRIS functions and DRIS indices.

For any $\left(\mathrm{X}_{1} / \mathrm{X}_{2}\right)$ nutrient ratio characterizing an independent tissue specimen, and given the mean and CV as DRIS norms for the ratio $\left(\mathrm{x}_{1} / \mathrm{x}_{2}\right)$ of target population, the DRIS function $\mathrm{f}\left(\mathrm{X}_{1} /\right.$ $\mathrm{X}_{2}$ ) is calculated by (Elwali and Gascho, 1983):

$$
\begin{aligned}
\mathrm{f}\left(\mathrm{X}_{1} / \mathrm{X}_{2}\right)=[ & {\left[\left(\mathrm{X}_{1} / \mathrm{X}_{2}\right) /\left(\mathrm{x}_{1} / \mathrm{X}_{2}\right)-1\right] *(1000 / \mathrm{C} \mathrm{V}), } \\
& \text { if }\left(\mathrm{X}_{1} / \mathrm{X}_{2}\right)>\left(\mathrm{x}_{1} / \mathrm{X}_{2}\right)
\end{aligned}
$$




$$
\begin{gathered}
\mathrm{f}\left(\mathrm{X}_{\mathrm{l}} / \mathrm{X}_{2}\right)=\underset{ }{\left[\left(1-\left(\mathrm{X}_{1} / \mathrm{X}_{2}\right) /\left(\mathrm{X}_{1} \mathrm{X}_{2}\right)\right]\right.} *(1000 / \mathrm{CV}), \\
\text { if }\left(\mathrm{X}_{1} / \mathrm{X}_{2}\right)<\left(\mathrm{X}_{\mathrm{l}} / \mathrm{X}_{2}\right)
\end{gathered}
$$$$
f\left(X_{1} / X_{2}\right)=0 \text { if }\left(X_{1} / X_{2}\right) \text { is within }\left(X_{1} / X_{2}\right) \pm S_{(x \mid 1 / 2)} \text {, }
$$

where $\mathrm{S}_{(\mathrm{x} / 1 / 2)}$ is the SD of the $\left(\mathrm{X}_{1} / \mathrm{X}_{2}\right)$ ratio for target population.

A DRIS index Ixi sums UP the $(\mathrm{d}-1)$ DRIS functions involving nutrient $X_{i}$ as:

$$
I_{x i}=[1 /(d-1)] * \sum_{i=1}^{d} f\left(X_{i} / X_{d}\right), i \neq i d,
$$

subjected to $f\left(X_{i} / X_{d}\right)=-f\left(X_{d} / X_{i}\right)$.

Equations $[5 \mathrm{a}-5 \mathrm{c}]$ require the proper choice of ratio expression, since $\operatorname{var}\left(\mathrm{x}_{1} / \mathrm{x}_{2}\right) \neq \operatorname{var}\left(\mathrm{x}_{2} / \mathrm{x}_{1}\right)$ may affect the value of DRIS norms (Beverly, 1987a). Walworth and Sumner (1989) reported that ratio expressions showing the highest variance ratio between low- and high-yielding populations should be selected.

An elegant solution, using logarithmic transformations compatible with the DRIS concept and improving nutrient diagnosis, was proposed by Beverly (1987b). The logarithmic transformation is statistically sound for ratios having different denominators (Steel and Torrie, 1980) and, as mentioned above, may improve distribution patterns of population nutrient ratios. Beverly (1987b) reduced Eqs. [5a] and [5b] to a single expression (which was originally multiplied by 10 to facilitate calculations):

$$
\mathrm{f}\left(\mathrm{X}_{1} / \mathrm{X}_{2}\right)=\left[1 / \mathrm{s}_{(\mathrm{x} \mid \times 2)}\right] *\left[\log \left(\mathrm{X}_{1} / \mathrm{X}_{2}\right)-\log \left(\mathrm{x}_{1} / \mathrm{X}_{2}\right)\right]
$$

Clearly, $f\left(X_{1} / X_{2}\right)=-f\left(X_{2} / X_{1}\right)$ and the DRIS function acquires independence of the way the logratio is expressed.

However, other problems still arise with the use of Eq. [6]. DRIS indices are computed as the mean value of dual ratio functions derived independently despite the bounded sum constraint. In addition, since only dual interactions are given diagnostic significance, higher-order interactions are not directly taken into account. The proposed way to sum up the bivariate DRIS functions also assumes function additivity (orthogonality). Nonadditivity of the DRIS functions would confound DRIS diagnoses even more when DRIS indices are summed up irrespective of sign to give a nutritional imbalance index, as shown by Alkoshab et al. (1988) for hazelnut. Therefore, the DRIS calculation procedure fails to fully recognize features of variability connected with a multidimensional space and spurious correlations between DRIS functions. These problems can be overcome by recognizing that DRIS functions are part of a dependence structure and have a common variance. DRIS functions should be reformulated as compositional functions of nutrient indices. For a given three-nutrient compositional array $\left(\mathrm{X}_{1}, \mathrm{X}_{2}, \mathrm{X}_{3}\right)$ used to compute a DRIS index $1_{\mathrm{x} 1}$ :

$$
\text { First assuming }\left[\mathrm{s}_{\mathrm{x} 1}\right]^{2}=\left[\mathrm{s}_{(\mathrm{x} \mid / \times 2)}\right]^{2}=\left[\mathrm{s}_{(\mathrm{x} \mid / \times 3)}\right]^{2}=\left[\mathrm{s}_{(\mathrm{x} 2 / \times 3)}\right]^{2}
$$

to signify a common variance among nutrient components of a structure-dependent (compositional) tissue data set,

$$
\begin{gathered}
\mathrm{Ix}_{1}=\left[1 /\left(2 * \mathrm{~S}_{\mathrm{x} 1}\right)\right] *\left\{\left[\log \left(\mathrm{X}_{1} / \mathrm{X}_{2}\right)-\log \left(\mathrm{x}_{1} / \mathrm{X}_{2}\right]+\right.\right. \\
\left.\left[\log \left(\mathrm{X}_{1} / \mathrm{X}_{3}\right)-\log \left(\mathrm{x}_{1} / \mathrm{X}_{3}\right)\right]\right\},
\end{gathered}
$$

where $\mathrm{S}_{\mathrm{X} 1}$ is the common SD for computing DRIS functions and where $I_{\mathrm{x} 1}=\mathrm{f}\left(\mathrm{X}_{1} / \mathrm{X}_{2}\right)+\mathrm{f}\left(\mathrm{X}_{1} / \mathrm{X}_{3}\right)$.

Rearranging Eq. [7], we obtain:

$$
\begin{gathered}
I_{x 1}=\left(1 /\left(2 * S_{x 1}\right)\right] *\left\{\left[2 * \log \left(x_{1}\right)-\log \left(X_{2}^{*} X_{3}\right)\right]-\right. \\
\left.\left[2 * \log \left(x_{1}\right) \log \left(x_{2}^{*} x_{3}\right)\right]\right\} .
\end{gathered}
$$

Adding and subtracting $\log \left(\mathrm{x}_{1}\right)$ or $\log \left(\mathrm{X}_{2}\right)$ within their respective brackets, then introducing divisor $\left(3 * \mathrm{~s}_{\mathrm{x} 1}\right)$ instead of $\left(2 * \mathrm{~s}_{\mathrm{x} 1}\right)$ to take this new inclusion into account, we obtain a new formulation of Eq. [8]:

$$
\begin{gathered}
\mathrm{Ix}_{1}=\frac{\left[1 /\left(3 * \mathrm{~S}_{\mathrm{x}}\right)\right]}{\left.\left[3 * \log \left(\mathrm{x}_{1}\right)-\log \left(\mathrm{x}_{1} * \mathrm{x}_{2} * \mathrm{X}_{3}\right)\right]\right\} .} \\
\left.\left[3 * \mathrm{X}_{3}\right)\right]-
\end{gathered}
$$

Equation [9] can be rearranged as:

$$
\mathrm{I}_{\mathrm{x} 1}=\left(1 / \mathrm{s}_{\mathrm{x} 1}\right) *\left\{\log \left[\mathrm{X}_{1} / \mathrm{g}(\mathrm{X})\right]-\log \left[\left(\mathrm{x}_{1}\right) / \mathrm{g}(\mathrm{x})\right]\right\}
$$

where $g(X)$ and $g(x)$ are the geometric means of specimen and target population compositions, respectively. Equation [10] can be generalized by replacing $X_{1}$ by $X_{i}$ and $x_{i}$ by $X_{i}$.

The generalized formulation of Eq. [10] is analogous to Eq. [2] when any row-centered logratio $\mathrm{Z}_{\mathrm{i}} \mathrm{is}$ compared with the corresponding row-centered logratio mean $\mathrm{z}_{\mathrm{i}}$ of the target population having a SD of $s_{z i}$. The DRIS index $I_{x i}$ is essentially a reduced (relative) distance between row-centered logratios if all DRIS functions are given the same SD, i.e., are integrated in a multivariate dependence structure. Thus, $I_{x i}\left(\right.$ renamed $I_{z i}$ ) is reduced to a comparison between two row-centered logratio means:

$$
I_{z i}=\left(Z_{i}-Z_{i}\right) / s_{z i} \cdot
$$

The $I_{i}$ value is a log linear contrast giving the appropriate distance between two components.

\section{Discussion}

Compositional nutrient diagnosis is based on a statistical theory developed for individuals characterized by compositional data sets, such as geological and biological specimens (Aitchison, 1986). CND expands the DRIS concept from a bidimensional to a multidimensional space. The dependence structure among compositional nutrient data accounted for by CND is conceptually linked to DRIS as shown by Eq. [10]. An expansion of the DRIS bivariate approach to the CND multivariate approach thus harmonizes the concepts elaborated by Beaufils (1973) and Aitchison (1982). CND recognizes high-order interactions between nutrients, which CVA failed to account for but which was partially addressed by DRIS. Since CND diagnoses one "nutrient imbalance" rather than one crude component at the time, the interpretation is as simple as, but theoretically more robust than, CVA. CND is connected to CVA and DRIS but, being based on compositional data analysis and principal component analysis, has greater potential for improving tissue diagnosis.

CND variates are computed from Eq. [2] for direct use along the proposed three lines: 1) drawing a yield $-\mathrm{z}_{\mathrm{i}}$ curve or diagram similar to the traditional graphical presentation of CVA with critical $z_{i}$ levels and a sufficiency range for each $z_{i}$, as illustrated by Walworth and Sumner (1989); 2) computing appropriate descriptive statistics (means and variance derivatives for $\mathrm{Z}_{\mathrm{i}}$ values) on compositional or subcompositional nutrient data sets from experimental or survey data and relating these statistics to yield, similarly to DRIS (Beaufils, 1973); 3) formulating principal components from $\mathrm{z}_{\mathrm{i}}$ values for mapping high-yielding crops in a space of reduced dimensions, analogous to that described by Aitchison (1983). Only compositional data sets situated outside the multidimensional body defined by high-yielding crops should be further diagnosed.

Interpretation of CND is based on the $I_{z i}$ index. The $I_{z i}$ index is the distance of a given nutrient $\mathrm{Xi}$ from its geometric mean 
$\mathrm{g}(\mathrm{X})$ relative to the distance of the same nutrient from the geometric mean $\mathrm{g}(\mathrm{x})$ of the target population:

$$
\begin{gathered}
\mathrm{I}_{\mathrm{zi}}=\left(1 / \mathrm{s}_{\mathrm{zi}}\right) *\left\{\left[\log \left(\mathrm{X}_{\mathrm{i}}\right)-\log (\mathrm{G}(\mathrm{X}))\right]-\right. \\
\left.\left[\log \left(\mathrm{x}_{1}\right)-\log (\mathrm{g}(\mathrm{x}))\right]\right\}
\end{gathered}
$$

Rearranging Eq. [12], we obtain:

$$
\begin{aligned}
\mathrm{I}_{\mathrm{zi}}= & \left(1 / \mathrm{s}_{\mathrm{zi}}\right) *\left\{\left[\log \left(\mathrm{X}_{\mathrm{i}}\right)-\log \left(\mathrm{x}_{\mathrm{i}}\right)\right]\right. \\
& +[\log (\mathrm{g}(\mathrm{x}))-\log (\mathrm{g}(\mathrm{X}))]\} .
\end{aligned}
$$

Thus, $I_{z i}$ is made up of two discrete functions:

$$
f\left(X_{1}\right)=\left[\log \left(X_{1}\right)^{-} \log \left(x_{1}\right)\right]
$$

and

$$
\mathrm{f}[\mathrm{g}(\mathrm{X})]=[\log (\mathrm{g}(\mathrm{x}))-\log (\mathrm{g}(\mathrm{X}))] .
$$

Walworth and Sumner (1989) reported on the difficulty of defining critical levels for deficiency in situations of multinutrient deficiency compared with situations suboptimal for only one nutrient and optimal for all others. In fact, the separation of a nutrient function $\mathrm{f}(\mathrm{X})$ and a function for geometric means $\mathrm{f}[\mathrm{g}(\mathrm{X})]$ indicate that $\mathrm{I}_{\mathrm{zi}}$ depends not only on individual nutrient levels but also on the position of $g(X)$ relative to $g(x)$ (Table $1)$. Thus, $\mathrm{I}_{\mathrm{zi}}$ compares two relative positions, nutrient level and nutrient balance. Neither the univariate CVA nor the bivariate DRIS procedures account for the difference between geometric means of target and independent specimens.

The difference in geometric means has ecological justifications. Actually, plant composition is a unique consequence of plant adaptation to a particular nutrient environment (Stuart Chapin, 1989) and represents an internal state of equilibrium reached by each specimen, which could differ from that of the target population. Thus, nutrient deficiency could be corrected by fertilizing according to the deficient nutrient to increase its level in the diagnosed tissue from $\mathrm{Xi}$ toward $\mathrm{x}_{\mathrm{i}}$, or by taking advantage of multiple interactions of that nutrient with other elements and fertilizing or liming in such a way to move $g(X)$ toward $\mathrm{g}(\mathrm{x})$ as well as $\mathrm{Xi}$ toward $\mathrm{x}_{\mathrm{i}}$.

Table 1. Theoretical interpretative table for $\mathrm{I}_{\mathrm{zi}}$, notwithstanding the possibility to establish a confidence interval about $\mathrm{I}_{\mathrm{zi}}$ to define nutrient balance $\left(\mathrm{I}_{\mathrm{zi}} \pm \mathrm{s}_{\mathrm{zi}}\right) . \mathrm{I}_{\mathrm{zi}}<0$ : relative nutrient insufficiency, $\mathrm{I}_{\mathrm{zi}}$ $=0$ : nutrient balance, $\mathrm{I}_{\mathrm{zi}}>0$ : relative nutrient excess.

\begin{tabular}{lccc}
\hline \hline \multirow{2}{*}{$\begin{array}{lcc}\text { Inequality or } \\
\text { equality }\end{array}$} & $\mathrm{X}_{\mathrm{i}}<\mathrm{x}_{\mathrm{i}}$ & $\mathrm{X}_{\mathrm{i}}=\mathrm{x}_{\mathrm{i}}$ & $\mathrm{X}_{\mathrm{i}}>\mathrm{x}_{\mathrm{i}}$ \\
\cline { 2 - 4 } $\mathrm{g}(\mathrm{X})<\mathrm{g}(\mathrm{x})$ & $\mathrm{a}^{\mathrm{y}}$ & $>0$ & $>0$ \\
$\mathrm{~g}(\mathrm{X})=\mathrm{g}(\mathrm{x})$ & $<0$ & 0 & $>0$ \\
$\mathrm{~g}(\mathrm{X})>\mathrm{g}(\mathrm{x})$ & $<0$ & $<0$ & $\mathrm{a}$ \\
\hline
\end{tabular}

${ }^{\mathrm{z}} \mathrm{X}_{\mathrm{i}}, \mathrm{X}_{\mathrm{i}}$ and $\mathrm{g}(\mathrm{X}), \mathrm{g}(\mathrm{x})$ : level of nutrient $\mathrm{X}_{\mathrm{i}}$ and geometric mean of composition array for independent specimen and target population, respectively.

'Trend for ' $a$ ' depends on magnitude of inequalities.
Notwithstanding theoretical considerations, the merit of using compositional nutrient diagnosis will depend on validation studies involving many fertilizer trials conducted independently. Should CND demonstrate high sensitivity for diagnostic purposes, a gap could be bridged between multivariate diagnosis and multivariate analysis, as anticipated by Holland (1966). Aitchison (1986) showed that compositional data analysis was an efficient procedure for conditioning raw data affected by a closure problem, before principal component analysis. Since tissue data sets form compositional data sets, multivariate methods could be further explored to assess nutrient status in plants.

\section{Literature Cited}

Aitchison, J. 1982. The statistical analysis of compositional data. J. Royal Stat. Sot. B 44(2):139-177.

Aitchison, J. 1983. Principal component analysis of compositional data. Biometrika 70:57-65.

Aitchison, J. 1984. Reducing the dimensionality of compositional data sets. Mathematical Geology 16:617-635.

Aitchison, J. 1986. Statistical analysis of compositional data. Chapman and Hall, New York.

Aitchison, J. 1989. Reply to "Interpreting and testing compositional data" by A. Woronow, K.M. Love, and J.C. Butler. [Letter to the Editor]. Math. Geol. 21:65-71.

Aitchison, J. 1990. Relative variation diagrams for describing patterns of compositional variability. Math. Geol. 22:487-51 1.

Alkoshab, O., T.L. Righetti, and A.R. Dixon. 1988. Evaluation of DRIS for juding the nutritional status of hazelnuts. J. Amer. Soc. Hort. Sci. 113(4):643-647.

Bates, T.E. 1971. Factors affecting critical nutrient concentrations in plants and their evaluation: a review. Soil Sci. 112:116-130.

Beaufils, E.R. 1973. Diagnosis and Recommendation Integrated System (DRIS). Soil Sci. Bul. no. 1, University of Natal, Pietermaritzburg, South Africa.

Beverly, R.B. 1987a. Comparison of DRIS and alternative nutrient diagnostic methods for soybean. J. Plant Nutr. 10(8):901-920.

Beverly, R.B. 1987b. Modified DRIS method for simplified nutrient diagnosis of 'Valencia' oranges. J. Plant Nutr. 10:1401-1408.

Elwali, A.M.O. and G.J. Gascho. 1983. Sugarcane response to P, K and DRIS corrective treatments on Florida Histosols. Agron. J. 75:7982.

Holland, D.A. 1966. The interpretation of leaf analysis. J. Hort. Sci. 41:311-329.

Jolliffe, I.T. 1986. Principal component analysis. Springer-Verlag, New York.

Steel, R.G.D. and J.H. Torrie. 1980. Principles and procedures of statistics. A biometrical approach. Second ed., McGraw-Hill, New York. p. 235.

Stuart Chapin III, S. 1989. Ecological aspects of plant mineral nutrition. Adv. Plant Nutr. 3:161-191.

Walworth, J.L. and M.E. Sumner. 1987. The Diagnosis and Recommendation Integrated System (DRIS). Adv. Soil Sci. 6: 149-188.

Walworth, J.L. and M.E. Sumner. 1989. Foliar diagnosis: a review. Adv. Plant Nutr. 3:193-241. 